\title{
Effects of Hydrogels on Soil Moisture and Growth of Cajanus cajan in Semi Arid Zone of Kongelai, West Pokot County
}

\author{
Cheruiyot Gilbert ${ }^{1 *}$, Sirmah Peter ${ }^{1}$, Ng'etich Wilson², Mengich Edward ${ }^{1,3}$ \\ Mburu Francis ${ }^{1}$, Kimaiyo Sylvester ${ }^{1}$, Bett Erick ${ }^{4}$ \\ ${ }^{1}$ School of Natural Resource Management, University of Eldoret, Eldoret, Kenya \\ ${ }^{2}$ School of Agriculture, University of Eldoret, Eldoret, Kenya \\ ${ }^{3}$ Kenya Forestry Research Institute, Londiani, Kenya \\ ${ }^{4}$ School of Science, University of Eldoret, Eldoret, Kenya \\ Email: "gilcheri@yahoo.com
}

Received September $8^{\text {th }}$, 2013; revised October 21 ${ }^{\text {st }}, 2013$; accepted November $9^{\text {th }}, 2013$

\begin{abstract}
Copyright (C) 2014 Cheruiyot Gilbert et al. This is an open access article distributed under the Creative Commons Attribution License, which permits unrestricted use, distribution, and reproduction in any medium, provided the original work is properly cited. In accordance of the Creative Commons Attribution License all Copyrights (C) 2014 are reserved for SCIRP and the owner of the intellectual property Cheruiyot Gilbert et al. All Copyright (c) 2014 are guarded by law and by SCIRP as a guardian.
\end{abstract}

Studies on the effects of hydrogels on soil amendments, moisture conservation and growth of Cajanus cajan in arid and semi-arid lands were carried out. Seedlings of $C$. cajan were established both in the nursery and in the field with and without hydrogels. In the field, three replications were used with three levels of hydrogels concentration $(7 \mathrm{~g}, 11 \mathrm{~g}$, and $15 \mathrm{~g}$ ). Control seedlings were established in soils without hydrogels. In the nursery, root collar diameters and heights were measured every two weeks up to eight weeks. Seedlings established without hydrogels in the nursery were transplanted into field soils with none, $7 \mathrm{~g}, 11 \mathrm{~g}$ and $15 \mathrm{~g}$ of hydrogels. Root collar diameters and heights were again measured every month for three months. In addition, soil was collected randomly once every month from the base of each seedling and analyzed for soil moisture using standard laboratory procedures. All data were subjected to analysis of variance. The results show that growth in both the height and root collar diameter of the species was significantly different at the three levels of hydrogels. This suggests that use of hydrogels retards plant growth in nursery soils but improves growth in the field. Hydrogels increased soil moisture volume from $8.3 \%$ to $10 \%$ in $\mathrm{H}_{15 \mathrm{~g}}$ level of hydrogels under $\mathrm{C}$. cajan after transplanting. It was concluded that hydrogels do not contribute to growth of seedlings in the nursery but they do so after transplanting. Hydrogels increase soil moisture in the soil, so they are recommended for use in semi-arid lands to boost the survival and growth of seedlings.

Keywords: Hydrogels; Moisture; Growth; Semi-Arid Lands

\section{Introduction}

Kenya is a developing country striving to achieve vision 2030 (Muchiri et al., 2009). One way of achieving the goals of Vision 2030 is by improving the livelihoods of people living in arid and semi arid lands through introduction of appropriate agroforestry technologies and practices to mitigate aridity (Okorie, 2003). Forest cover in Kenya is currently standing at $1.7 \%$ way below the internationally accepted minimum of $10 \%$ (IPCC, 2008), thus there is need to support the development of forestry practices to increase forest cover towards the required minimum percentage. On the basis of moisture availability for plant growth, Kenya is classified as $88 \%$ arid and semi-arid with a population of over 10 million, many of whom are pastoralists and agro-pastoralists (GoK, 2010). Similarly, moisture retention in the soil is important for the growth of agroforestry tree species. Soil water affects plant growth directly because it influences aeration, temperature, nutrient transport, uptake and transformation (Luo et al., 2011).

Hydrogels are networks of polymer chains that are hydro"Corresponding author. philic and highly absorbent to water molecules (Abedi-Koupai, 2008). The addition of hydrogels to soil can improve water holding capacity, decrease evapotranspiration and allow plants to mitigate the drought stress (Chirino et al., 2008).

This study therefore aimed at investigating the effects of hydrogels on soil water availability and growth of $C$. cajan seedlings in the nursery and during early establishment in the field. It was carried out in the arid and semi-arid areas of Kongelai.

\section{Materials and Methods}

\section{Location and Climate of Study Area}

This study was carried out at Kongelai, West Pokot County, Kenya (Figure $1 ; 1.47^{\circ} 71^{\prime} \mathrm{S}, 35.02^{\circ} 07^{\prime} \mathrm{E}$ ). The study area lies between $1500 \mathrm{~m}$ and $2100 \mathrm{~m}$ above sea level, and is characterized by a bimodal type of rainfall with the long rains between April and August and short rains between October and February. The area is characterized by great variations in temperature with $30^{\circ} \mathrm{C}$ in the lowlands and $15^{\circ} \mathrm{C}$ in the highlands.

The hydrogels used was "Belsap" manufactured by Bell 


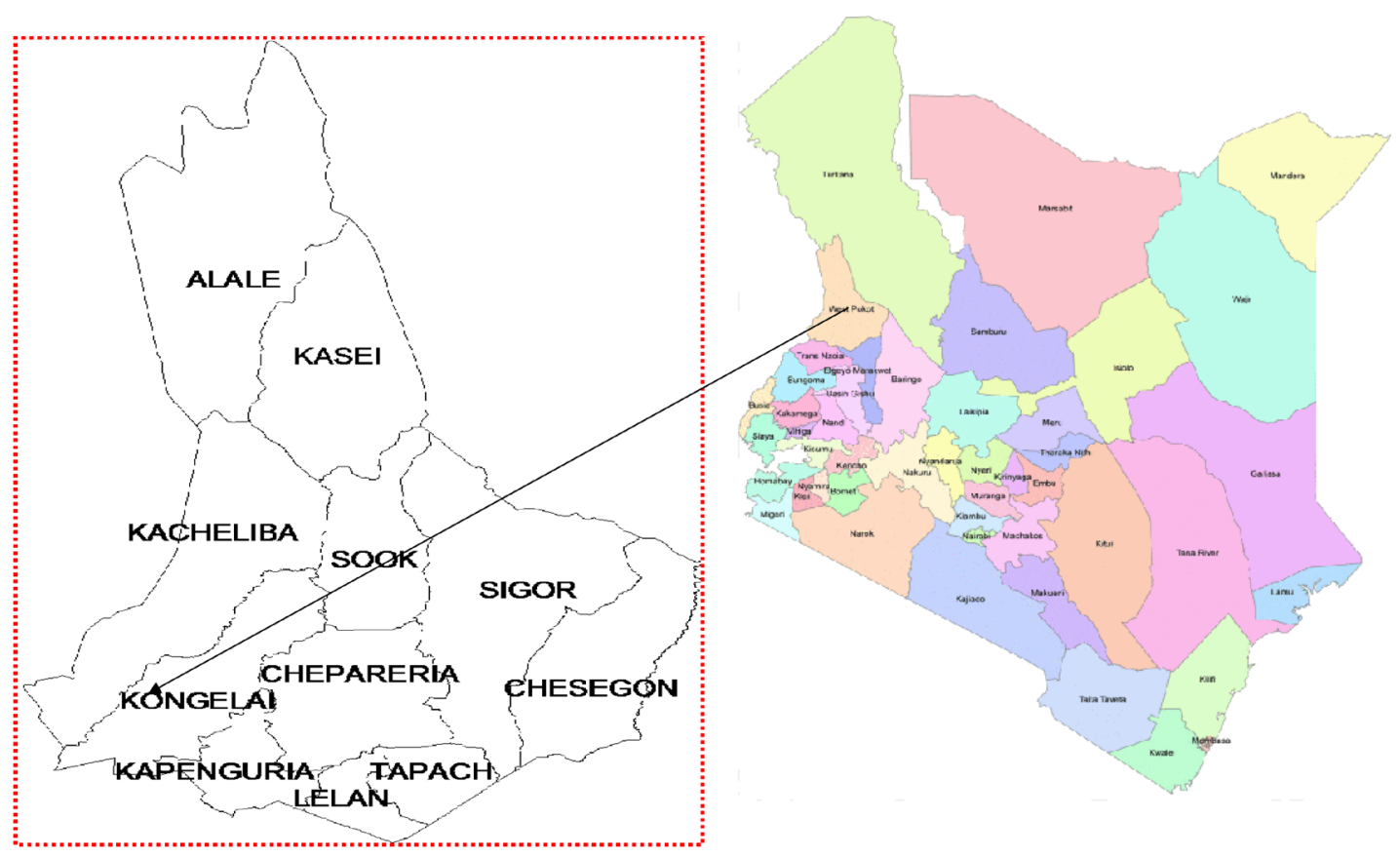

Figure 1.

Map of study area, West Pokot County (County Commissioner’s Office, 2013).

Industries limited in Nairobi Kenya.

Potting soil was obtained from Kapolet Forest Station within the county.

\section{Procedures in the Nursery}

Seeds of $C$. cajan were directly sown into polythene tubes measuring $4 \times 6$ inches containing $800 \mathrm{~g}$ of forest soil and at different levels of hydrogels. A total of 4 treatments of different levels of hydrogels: 0, 7, 11 and 15 g were prepared. Each consisted of 42 seedlings and replicated thrice. Treatments were randomized within the blocks. All polythene tubes were labeled for identification purposes. Once the seedlings germinated, root collar diameter and height were measured every two weeks for two months. A Randomized Complete Block Design (RCBD) was used in this experiment.

\section{Procedures in the Field}

After two months in the nursery, control seedlings were de-potted and transplanted into pre-tested soil samples in a field within the same region. Seedlings treated with hydrogels were not transplanted. In the field, the same levels of hydrogels as in the nursery were applied in the planting holes and mixed with soil. Thirty seedlings were used for each treatment. Once a month for two months, RCD and height of seedlings were measured. In addition soil samples were collected from the base of each growing seedling for moisture analysis.

\section{Determination of Soil Moisture}

$50 \mathrm{~g}$ soil from $0-10 \mathrm{~cm}$ horizons were collected in the field under Cajanus cajan seedlings using a soil auger seedlings. Initial weight was determined and the sample oven-dried at $100^{\circ} \mathrm{C}$. Oven dry weight was determined and soil moisture content determined.
The data collected were analyzed using Microsoft Excel; Analysis Toolpak, a computer package for data analysis. F-test was used to test the level of significance.

\section{Results and Discussion}

\section{Effects of Hydrogels on the Growth of Seedlings in the Nursery}

Cajanus cajan seedlings established in soils with no hydrogels gave higher height growth than those in soils treated with hydrogels (Figure 2). Soils treated with the higher amount of hydrogels (H15 g) gave the least growth in height of the seedlings. Analysis of variance for the height of Cajanus cajan seedlings showed that $\left\{\mathrm{F}_{0.05}(1)[3,15]=3.6182>\mathrm{F}\right.$ critical (3.4903) $\}$ implying that hydrogels application had a significant effect on the height growth.

Cajanus cajan seedlings established in soils with no hydrogels gave higher RCD growth compared to those established in soils treated with hydrogels (Figure 3 ). Analysis of variance showed that $\left\{\mathrm{F}_{0.05}(1)[3,15]=6.9127>\mathrm{F}\right.$ critical $\left.(6.2913)\right\}$ implying that hydrogels application had a significant effect on the root collar diameter growth.

Increasing levels of hydrogels had a negative effect on the growth of seedlings in the nursery both in height and RCD (Figures 2 and 3). Hydrogels also absorb water and fill the soil pores causing flooding in the polythene tubes therefore retarding the growth of seedlings (Del Campo et al., 2011; Korsaeth, 2012).

Effects of Hydrogels on the Growth of Seedlings in the Field

Cajanus cajan seedlings grown in soils with no hydrogels gained lower growth in height than those in soils treated with hydrogels (Figure 4). Analysis of variance for the height of 


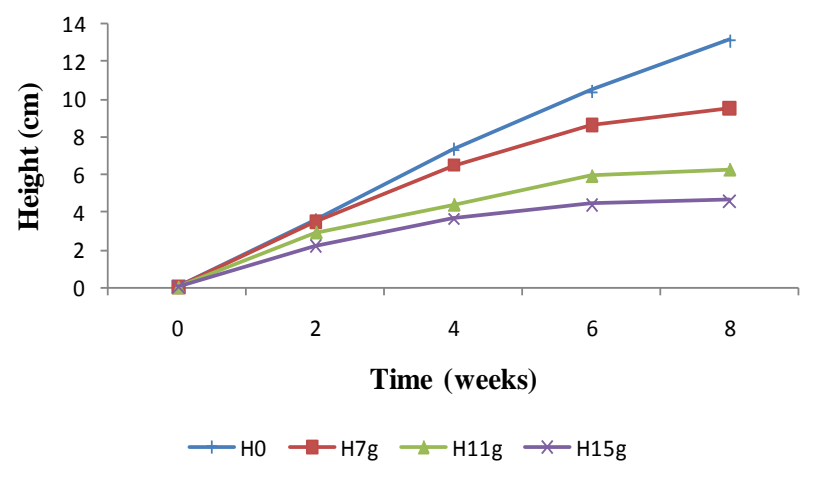

Figure 2.

Effects of hydrogels on height of Cajanus cajan seedlings in the nursery.

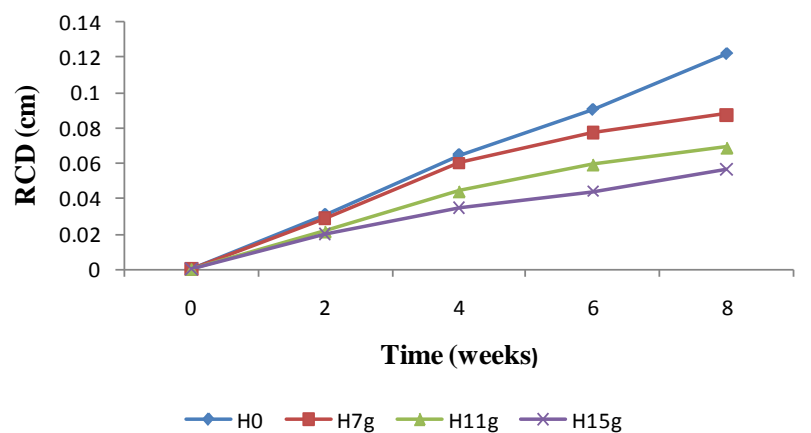

Figure 3.

Effects of hydrogels on RCD of Cajanus cajan seedlings in the nursery.

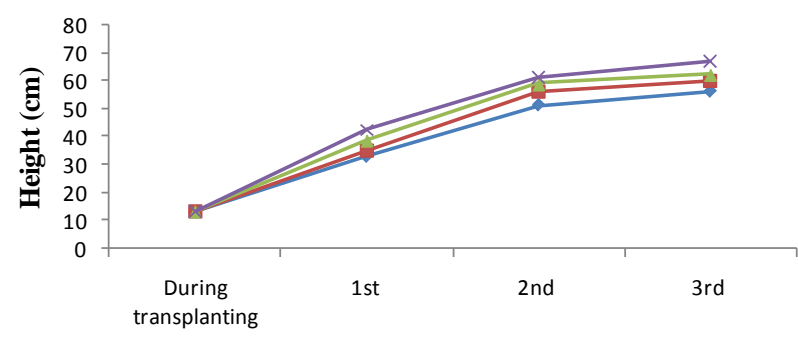

Time (Months)

$$
\multimap \text { HO } \rightarrow-H 7 g \rightarrow H 11 g \rightarrow H 15 g
$$

Figure 4.

Effects of hydrogels on height of transplanted seedlings after 3 months.

Cajanus cajan showed that $\left\{\mathrm{F}_{0.05}(1)[3,15]=144.8962>\mathrm{F}\right.$ critical (3.4903)\}. This showed that hydrogels had a significant effect on the growth of transplanted seedlings hence use of hydrogels to amend soils in the field had a positive impact on height growth.

Cajanus cajan seedlings grown in soils with no hydrogels gained least growth in RCD compared with those in soils treated with hydrogels (Figure 5). Analysis of variance for the height of Cajanus cajan showed that $\left\{\mathrm{F}_{0.05}(1)[3,15]=138.89>\mathrm{F}\right.$ critical (3.4903)\}. This showed that hydrogels had a significant effect on the growth of transplanted seedlings hence use of hydrogels in soils in the field has a positive impact on RCD growth.
Hydrogels is used in arid and semi-arid areas to improve the growth of agroforestry tree species. They absorb water, improving growth of transplanted seedlings under arid conditions (Chen et al., 2010). The results of Chen et al. (2010) confirm that changes in soil nutrient status were influenced by the application of hydrogels which led to the increase in soil fertility and hence the differences in growth rate.

\section{Effects of Hydrogels on Soil Moisture}

Soil moisture contents were determined in subplots under the species. Results are presented in Figure 6. In the arid and semi arid climate, hydrogels had an impact on soil moisture content in the soil after transplanting. Analysis of variance showed that; $\mathrm{F}_{0.05}(1)>\mathrm{F}$ critical, implying that hydrogels had a significant effect on the growth of transplanted seedlings in the field.

Landis (2012) reported that hydrogels improved soil moisture content and provided water to the plants during dry seasons. This was experienced in soils treated with hydrogels that gained more soil moisture as compared to controls.

\section{Conclusion}

Hydrogels retarded growth of seedlings in the nursery but improve the same after transplanting. They increase soil moisture content under arid and semi-arid conditions, therefore increasing seedlings survival after transplanting.

Further studies need to be done to compare the effects of hydrogels on a range of soil types using a wide range of tree species.

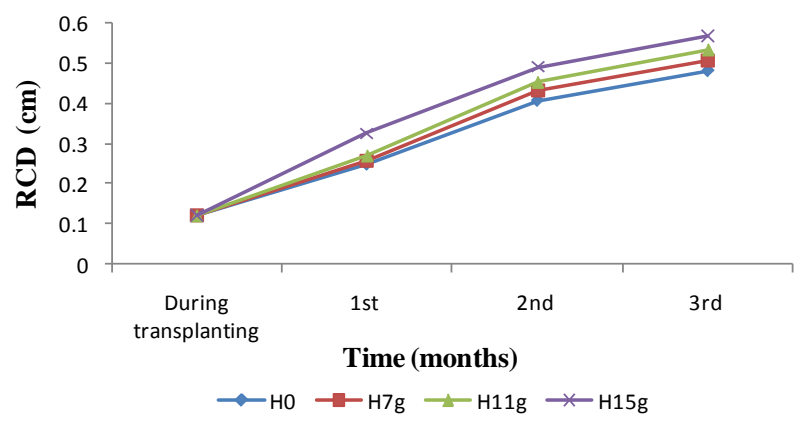

Figure 5.

Effects of hydrogels on height of transplanted seedlings after 3 months.

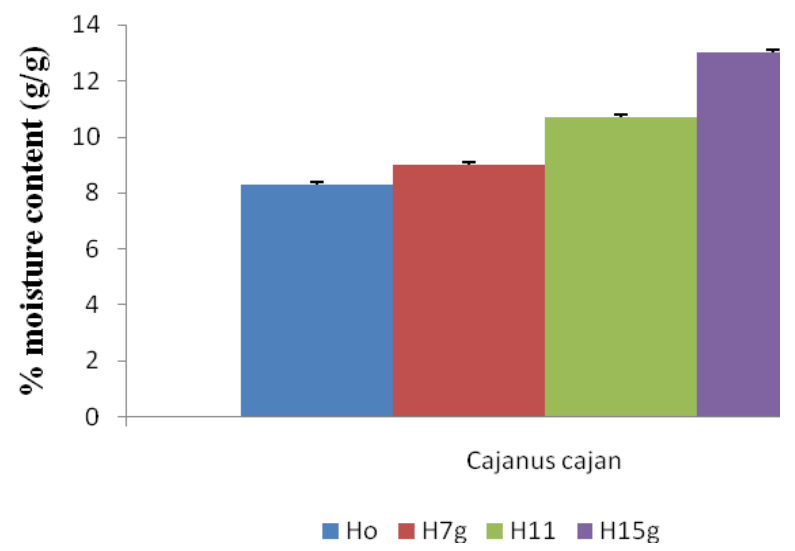

Figure 6.

Effects of hydrogels on soil moisture after transplanting. 


\section{REFERENCES}

Abedi-Koupai, J., Sohrab, F., \& Swarbrick, G. (2008). Evaluation of hydrogels application on soil water retention characteristics. Journal of Plant Nutrition, 31, 317-331. http://dx.doi.org/10.1080/01904160701853928

Chen, M. S., Huang, Y., Zou, J, W., Shen, Q, R., Hua, Z. H., Qin, Y, M., Chen, H, S., \& Pan, G. X. (2010). Modeling inter-annual variability of global soil respiration from climate and soil properties. Nanjing: College of Environmental Science and Engineering.

Chirino, E., Vilagrosa, A., Cortina, J., Valdecantos, A., Fuentes, D., Trubat, R., Luis, V. C., Puértolas, J., Bautista, S., Baeza, J., Peñuelas, J. L., \& Vallejo, V. R. (2008). Ecological restoration in degraded drylands: the need to improve the seedling quality and site conditions in the field. In S. P. Grossberg (Ed.), Forest management (pp. 85158). New York: Nova Science Publishers, Inc.

Del Campo, A. D., Hermoso, J., Flors, J., Lidon, A., \& Navarro-Cerrillo, R. M. (2011). Nursery location and potassium enrichment in Aleppo pine stock 2. Performance under real and hydrogels-mediated drought conditions. Forestry, 84, 235-245.

http://dx.doi.org/10.1093/forestry/cpr009

GoK (2010). National climate change response strategy. Nairobi: Ministry of Environment and Mineral Resources, Government of Kenya.

IPCC, (2008). Climate Change and Water, Intergovernmental Panel on
Climate Change Technical Report IV. June 2008.

Korsaeth, A. (2012). N, P, and K budgets and changes in selected topsoil nutrients over 10 years in a long-term experiment with conventional and organic crop rotations. Kapp: Norwegian Institute for Agricultural and Environmental Research.

Landis, T. C., \& Haase, D. L. (2012). Applications of hydrogels in the nursery and during out planting. In: D. L. Haase, J. R. Pinto, L. E. Riley, \& Technical Coordinators (Eds.), National Proceedings: Forest and Conservation Nursery Associations 2011 (pp. 53-58). Fort Collins, CO: USDA Forest Service, Rocky Mountain Research Station.

Luo, Z. K., Wang, E. L., Sun, O. J., Smith, C. J., \& Probert, M. E. (2011). Modeling long-term soil carbon dynamics and sequestration potential in semi-arid agro-ecosystems. Agricultural and Forest Meteorology, 151, 1529-1544.

Muchiri, K., Ochieng, B., Tuwei, P., \& Wanjiku (2009). Kenya Forestry Research Institute Proceedings of the 4th KEFRI Scientific Conference. Recent advances in forestry research for environmental conservation, improved livelihood and economic development. Muguga: KEFRI.

Okorie, F. C. (2003). Studies on drought in the Sub-Saharan Region of Nigeria using satellite remote sensing and precipitation data. Lagos: University of Lagos. 